\title{
The Advanced Dvorak Technique (ADT) for Estimating Tropical Cyclone Intensity: Update and New Capabilities
}

\author{
TimOthy L. OlANDER AND CHRISTOPHER S. VELDEN \\ Cooperative Institute for Meteorological Satellite Studies, University of Wisconsin-Madison, Madison, Wisconsin
}

(Manuscript received 16 January 2019, in final form 13 May 2019)

\begin{abstract}
The advanced Dvorak technique (ADT) is used operationally by tropical cyclone forecast centers worldwide to help estimate the intensity of tropical cyclones (TCs) from operational geostationary meteorological satellites. New enhancements to the objective ADT have been implemented by the algorithm development team to further expand its capabilities and precision. The advancements include the following: 1) finer tuning to aircraft-based TC intensity estimates in an expanded development sample, 2) the incorporation of satellitebased microwave information into the intensity estimation scheme, 3) more sophisticated automated TC center-fixing routines, 4) adjustments to the intensity estimates for subtropical systems and TCs undergoing extratropical transition, and 5) addition of a surface wind radii estimation routine. The goals of these upgrades and others are to provide TC analysts/forecasters with an expanded objective guidance tool to more accurately estimate the intensity of TCs and those storms forming from, or converting into, hybrid/nontropical systems. The 2018 TC season is used to illustrate the performance characteristics of the upgraded ADT.
\end{abstract}

\section{Introduction}

The advanced Dvorak technique (ADT) is a computerbased algorithm used to estimate the intensity of tropical cyclones (TCs) using geostationary satellite infrared imagery (Olander and Velden 2007). It is employed by most operational tropical cyclone analysis and forecasting centers (OpCen) worldwide to aid in determining the intensity of TCs, especially in oceanic basins where in situ measurements are not available.

The technique was first developed in the mid-1990s at the University of Wisconsin-Madison. This initial version of the algorithm was called the objective Dvorak technique (ODT; Velden et al. 1998) since it was closely modeled after the manual Dvorak technique (Dvorak 1975, 1984), which was a pattern-matching and satellite classification scheme developed in the late 1970s and early 1980s by Vern Dvorak of NOAA (Velden et al. 2006). The ODT was the first attempt to automate the entire Dvorak technique process and attempt to eliminate some of the inherent subjectivity. While partially successful, the ODT was limited to analyzing cyclones of strong tropical storm and hurricane/typhoon intensity only. The ODT was also completely reliant upon the user to provide/determine the storm center position,

Corresponding author: Timothy L. Olander, timo@ssec.wisc.edu which could lead to different intensity estimate solutions from the same satellite image depending on the selected storm center location. Despite these issues, the ODT was proven to be "getting close to" the estimates derived from the subjective Dvorak technique at several OpCens (Velden et al. 1998).

The next major release of the algorithm addressed these two algorithm shortcomings; expansion of the application range to include tropical depressions and weak tropical storms, and the integration of an objective storm center determination technique. This algorithm was called the advanced objective Dvorak technique (AODT) (Olander et al. 2002). The AODT could be activated and run in a completely objective and automated fashion once an OpCen began issuing bulletins on a selected TC.

Finally, in the mid- and late 2000s, several new technique advancements were implemented into the algorithm. These advancements went beyond the scope defined by the original Dvorak technique, so the algorithm was renamed the advanced Dvorak technique to highlight the progression beyond the original principles (Olander and Velden 2007). These advancements included: an improved objective stormcenter determination process, the use of regression-based analysis to derive intensity estimates for storms possessing an eye or a central dense overcast, and modifications 


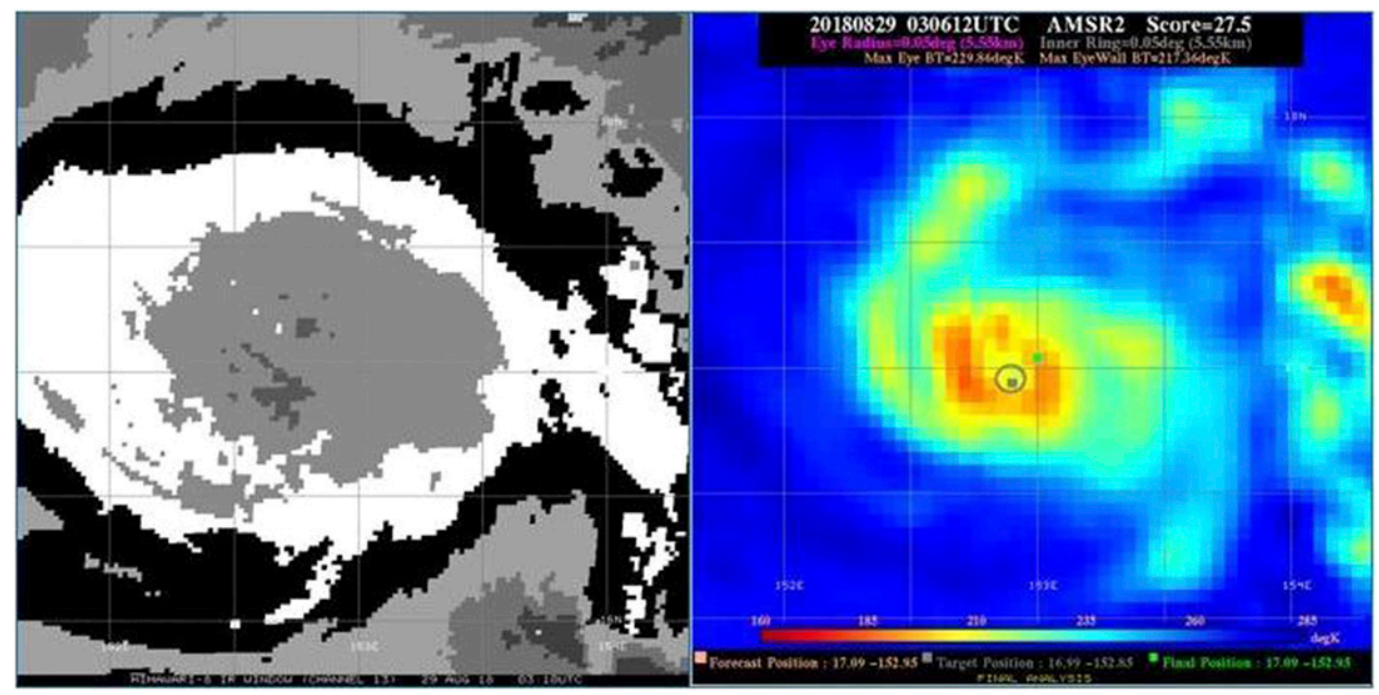

FIG. 1. (left) IR image showing a cold dense overcast cirrus canopy obscuring an eye feature captured in the (right) coincident PMW image for Typhoon Jebi (2018).

to the original Dvorak technique intensity constraint/ change rules.

Since Olander and Velden (2007) introduced the ADT, the algorithm has become operationally implemented and supported by NOAA/NESDIS. The ADT is now an established tool for providing realtime objective TC intensity guidance at OpCens around the globe. Real-time estimates are also publically available via the UW-CIMSS Tropical Cyclone web page (http://tropic.ssec.wisc.edu), where TC researchers can also download the code for local explorations. Further development of the ADT has continued in the last decade in response to user feedback, new science, and improvements in satellite sensors. These advancements, including the algorithm functionality improvements introduced in two major releases (version 8 and version 9) are discussed in section 2 and 3. Section 4 presents an updated validation summary, including global ADT comparisons to OpCen best tracks and Dvorak technique estimates, as well as highlighted examples of ADT performance behavior for selected storms during the past few years.

\section{ADT version 8}

The ADT algorithm has undergone several major and many minor revisions since the Olander and Velden (2007) article. Two major functionality upgrades were included in the version 8 series, first released in late 2009 , along with several minor upgrades, and will be discussed in this section. The ADT version 9 will be discussed in the following section.

\section{a. Inclusion of passive microwave information}

The ADT operates on infrared (IR) imagery provided by geostationary satellites. The version 8 algorithm included a major advancement: incorporation of polar-orbiter satellite microwave observations. The use of 85-91-GHz passive microwave (PMW) information was implemented to address a noted weakness of the IR-based ADT and AODT (and to some extent the manual Dvorak technique): the limited ability to properly diagnose intensification when the central dense overcast (CDO) is masking increased convective organization and developing eyewall structure. This situation often results in an intensity "plateau" that persists until an eye appears in IR imagery. PMW observations can see through the CDO cirrus canopy and depict the evolving convective structures (Hawkins et al. 2001). An example is shown in Fig. 1.

The utilization of PMW information allows the ADT to observe a forming eye, and if conditions are met, override the IR-based intensity estimate. The PMW intensity analysis scheme (Wimmers and Velden 2010; Sears et al. 2010) derives an "eye score" value related to the organization and vigor of the eye/eyewall features in the PMW imagery. The score is determined by examining the amount of eyewall "wrap" (organization) and the difference between the coldest measured brightness temperatures of the pixels within the eyewall region and the warmest pixel within the eye (vigor). The resulting eye score values fall between 0 and 100, and these are then broadly related to current TC intensity. The technique is only able to confidently relate the eye score values to TC intensity (hereafter defined as Vmax, for 


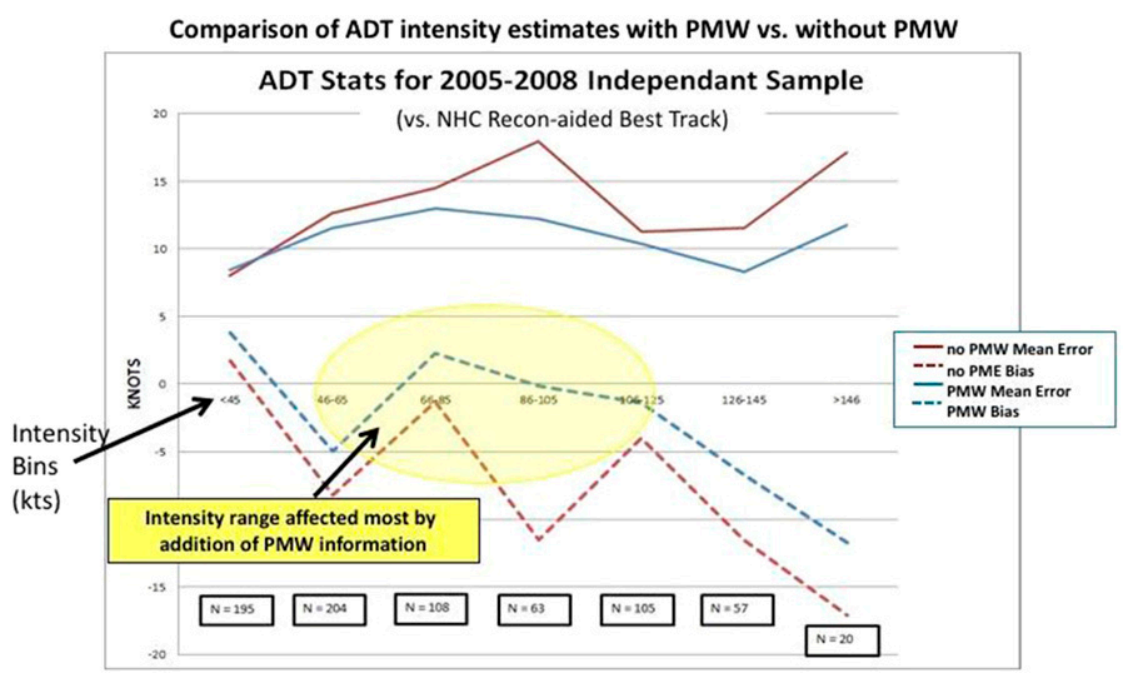

FIG. 2. Impact of PMW adjustments on ADT intensity analyses. Statistics display ADT without PMW adjustment (red lines) vs with PMW adjustment (blue lines). The shaded area shows the Vmax range most directly impacted.

maximum sustained 1-min, 10-m wind) within two ranges: an eye score between 20 and 60 indicates a TC intensity greater than $72 \mathrm{kt}\left(1 \mathrm{kt} \approx 0.51 \mathrm{~m} \mathrm{~s}^{-1}\right)$, and a score $\geq 60$ indicates a storm intensity greater than $90 \mathrm{kt}$. These wind speeds correspond to Dvorak current intensity numbers (CI\#) of 4.3 and 5.0, respectively, and are the values inserted into the ADT when the thresholds are achieved (the relative crudeness of the PMW intensity override methodology is acceptable in this case since the ADT application only triggers in certain situations and over a limited intensity range).

Once the eye score value exceeds one of the thresholds, a check is performed against a basin-appropriate OpCen estimate of Vmax, which must be at least $55 \mathrm{kt}$ for the PMW override to trigger. This threshold was introduced as a check against false alarms that can occur when a weak transitory PMW eye signature prematurely signals intensification. Occasionally, as with any threshold-based decision in an objective algorithm, this constraint can inhibit a real intensification signal not yet indicated in the OpCen estimates, but the threshold of $55 \mathrm{kt}$ was set based on empirical evidence that the constraint is beneficial in the majority of cases. If this criterion is met, the ADT CI\# at the PMW overpass time (this can be $1-6 \mathrm{~h}$ prior to analysis time due to data downlink and processing delays) is directly modified in the ADT history file (running log of intensity estimates and other parameters) to 4.3 or 5.0. To avoid unrealistic intensity jumps, the new CI\# is backblended into the history file by linearly interpolating between the modified value and the CI\# value of the record $12 \mathrm{~h}$ previous (the original values are saved in the comments section with each record). Going forward, if the PMW eye score remains between 20 and 60, the ADT CI\# values are steadily increased from 4.3 to 4.8 over the next $12 \mathrm{~h}$ (the Dvorak model rate of change) unless the logic is disabled by one of four events: 1 ) the eye score value falls below 20 in any subsequent PMW analysis, 2) "eye" scene types (IR) are analyzed in three consecutive 30-min IR images, 3) curved band or shear scene types are analyzed in three consecutive 30-min IR images, or 4) the PMW eye score does not update for 8 consecutive hours. In any of these cases the use of the PMW logic will turn off and the ADT will revert to the normal rules for IR imagery analysis. If the PMW eye score increases to $\geq 60$, the ADT CI\# is set to 5.0, and in a similar manner as before, the history file is back blended. Once the CI\# has increased to 4.8 or 5.0, the value is held until the one of the four termination events occur.

It should be noted that the PMW adjustment scheme is only performed during storm intensification, basically to help bridge the intensity "plateau" noted earlier. PMW values are not employed during eye stages (IR is superior) or storm weakening (PMW structures become a less reliable indicator of current intensity). Once the ADT CI\# falls below 4.0, the PMW adjustment scheme can once again be activated if the storm reintensifies.

The statistical impact of the PMW adjustment on ADT intensity performance is displayed in Fig. 2. The analysis is based on an independent test sample of TC cases with reconnaissance aircraft verification in the North Atlantic from 2005 to 2008 when the methodology was being developed and implemented. The utilization of the PMW adjustment clearly shows an overall reduction in the intensity estimation errors, and 


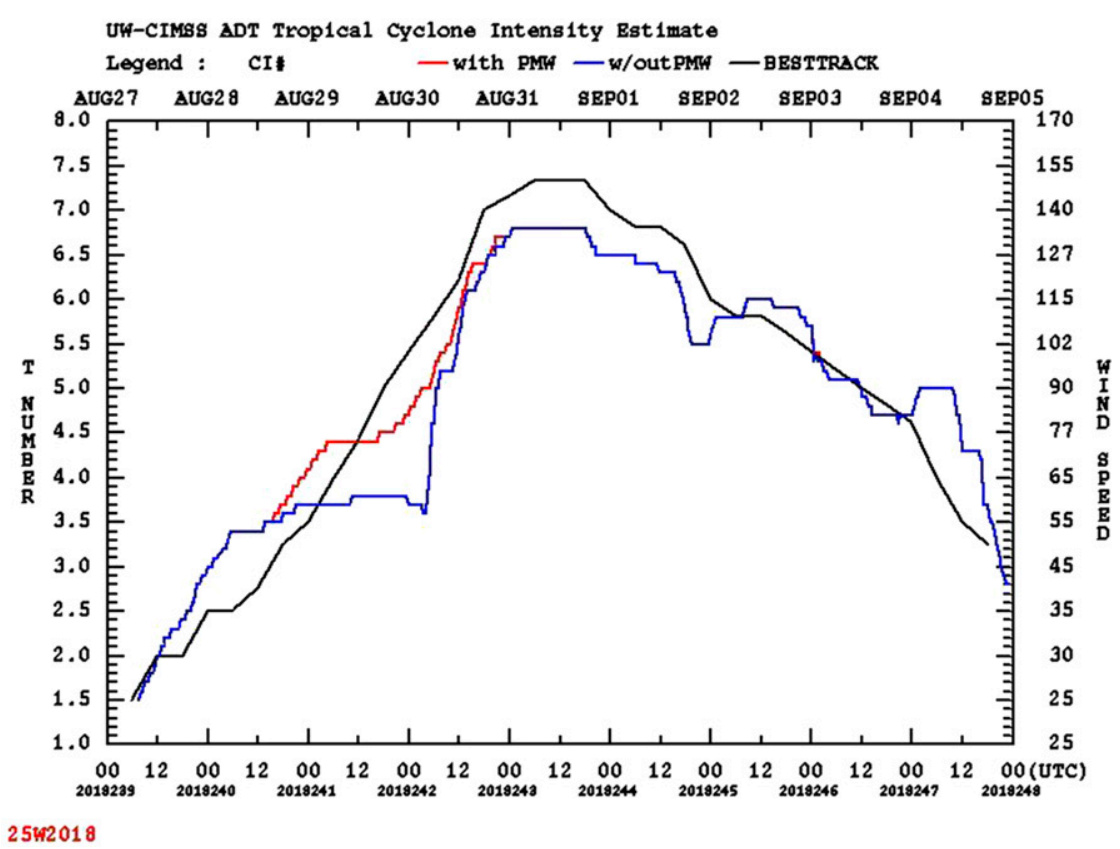

FIG. 3. Impacts resulting from PMW eye score adjustments on ADT intensity analysis of Super Typhoon Jebi $(25 \mathrm{~W})$. The red line (blue line) is the ADT intensity estimates (Vmax; kt) with (without) the PMW adjustment scheme. The black line is the JTWC best track intensity.

in particular within the TC intensity ranges most affected by the CDO plateau weak bias. It is also noted that even the much higher intensity bins are impacted somewhat due to the ADT having less need to "catch up" with the actual storm intensity after the appearance of an eye.

Figure 3 illustrates an example of PMW modification of the ADT intensity history for Typhoon Jebi $(25 \mathrm{~W})$ in 2018. The CDO plateau is clearly evident in the nonPMW plot between approximately 1500 UTC 28 August and 0500 UTC 30 August, after which the eye finally appeared in the IR imagery. Use of a PMW analysis first initiated at 0300 UTC 29 August, adjusting the CI\# to 4.3 (and modifying the previous $12 \mathrm{~h}$ ). After a short intensity " "hold" " period due to fluctuating PMW scores around the 20 threshold, the intensity then slowly increased from 4.3 to 4.6 until 0300 UTC 30 August when an eye score value came in above 60 , which then increased the CI\# to 5.0 (with the CI\# being modified back $12 \mathrm{~h}$ ). The PMW adjustment then was discontinued at 0500 UTC 30 August after the consecutive IR eye rule was met, and in this case the two intensity estimate curves eventually merge back up (not always the case). Even though the intensity plateau is not completely eliminated, it can be seen that the ADT with PMW intensity trend much more closely matches the Joint Typhoon Warning Center (JTWC) best track over this time period.
An obvious limitation of the PMW data is the infrequent availability due to orbital characteristics. Overpasses that miss the key TC convective structures can cause issues with ADT estimates that will be discussed in section 4. However, the positive impact of PMW data when they are available during TC intensification phases is clearly shown to be an important enhancement to the ADT intensity accuracy. Currently (as of 2019), PMW data are available from the Global Precipitation Measurement Microwave Imager (GMI), Advanced Microwave Scanning Radiometer 2 (AMSR2), the Special Sensor Microwave Imager (SSM/I) aboard the Defense Meteorological Satellite Program (DMSP) F15 satellite, and SSMI Sounder (SSM/IS) aboard the DMSP F16, F17, and F18 satellites. In the future, as high-resolution PMW imagers are lost (e.g., SSM/IS), there will be a need to incorporate new PMW sensors, some that may be lower in spatial resolution. It is unclear what impact this might have on the ADT's performance, but this will need to be explored.

\section{b. Courtney-Knaff-Zehr wind-pressure relationship}

The second major implement to the version 8 ADT involved the incorporation of the Courtney-Knaff-Zehr wind-pressure relationships (CKZ) to better determine the corresponding estimates of TC minimum sea level pressure (MSLP). These relationships are described in 


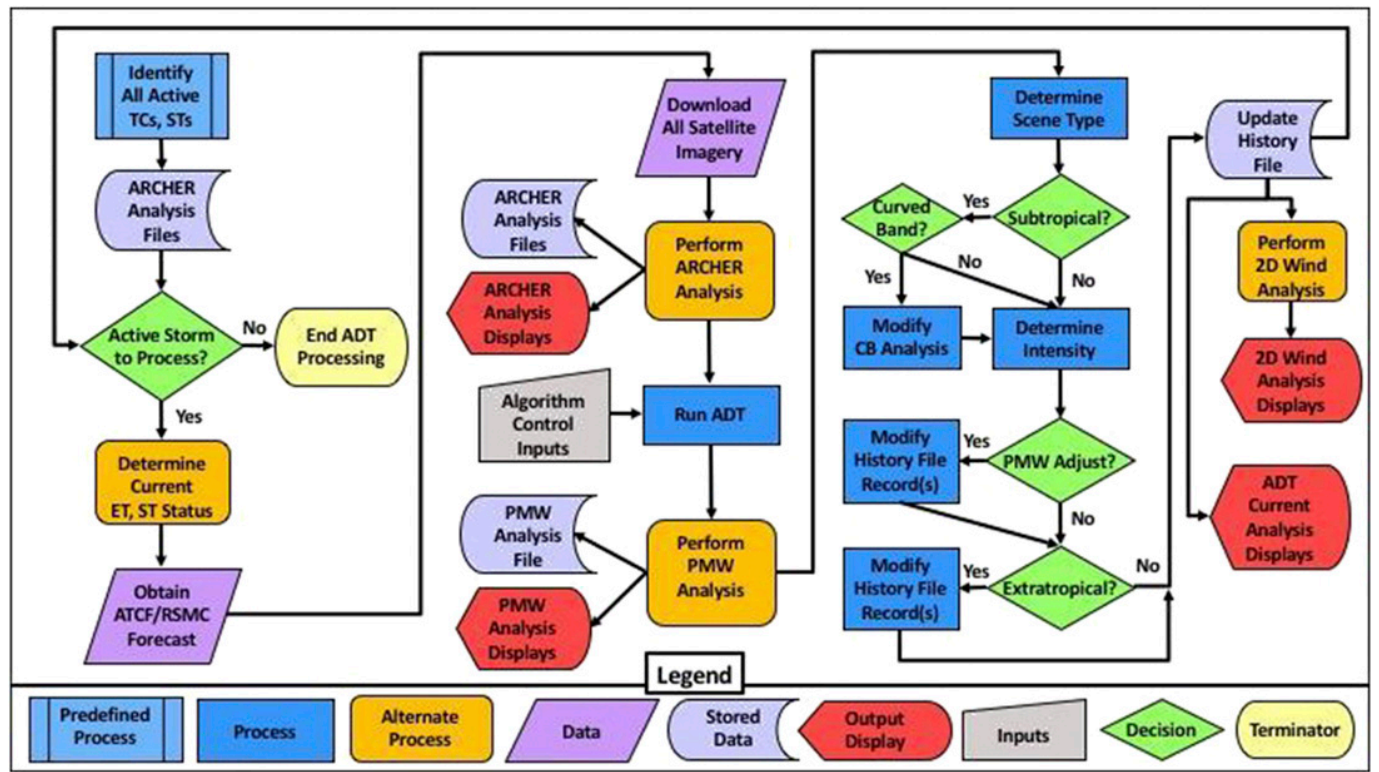

FIG. 4. Basic ADT algorithm processing overview.

Knaff and Zehr (2007) and Courtney and Knaff (2009). They replace the standard Dvorak pressure-wind relationships. The CKZ method utilizes several environmental parameters along with the ADT-derived CI\# number to estimate the MSLP. All of the environmental values can be obtained in real time from the ATCF best track/objective aid/wind radii format files using the observational comprehensive archive (CARQ) record values (Sampson and Schrader 2000). Impacts of this implementation will be discussed in section 4.

\section{c. Other modifications}

Several other algorithm improvements of note were included in the version 8 ADT. First, the ability to utilize WMO RSMC/ICAO format forecast files was added for the automated storm center determination process. This optional capability can be employed outside of the NOAA/National Hurricane Center (NHC) Area of Responsibility (AOR) where either bulletins or ATCF forecast ("a-deck") files from JTWC or NOAA/Central Pacific Hurricane Center (CPHC), are primarily utilized. This added capability allows local RSMC/ICAO forecast centers to obtain ADT estimates utilizing their own official forecasts to initiate TCs and provide the default objective storm center positions. The operational ADT run at NOAA/NESDIS currently operates in both modes.

Second, various Dvorak technique rules affecting allowable intensity changes (i.e., flowchart steps 8 and 9; Dvorak 1984) were modified in version 8 based on extensive statistical analysis of the ADT situational behavior. These rule changes included a relaxing of constraints on the amount of tropical number (T\#) change over time depending on various ADT scene types and the TC basin. For example, more rapid weakening is tolerated (allowing faster degeneration of the ADT CI\# over time) for east Pacific storms that can move quickly over sharper ocean surface temperature gradients into colder water.

Finally, adjustments were made to the version 8 ADT Eye scene regression equations. There are three separate equations for the Atlantic/east-central Pacific basins, northern west Pacific basin, and "other" basins (including the Indian Ocean and southern Pacific) based on interbasin validation studies. In general, these modifications resulted in slightly stronger intensities for the Atlantic/east-central Pacific and northern west Pacific basin equations only when the coud region temperature values (convective ring around the eye) are extremely cold, since a slight intensity underestimate bias was observed in earlier ADT versions with $\mathrm{CI} \# \geq 7.0$.

\section{ADT version 9}

Released in mid-2018, the version 9 ADT includes significant enhancements to the functionality of the algorithm. Figure 4 shows an overview flowchart of the current ADT algorithm, including the new processing options introduced in both the version 8 and version 9 upgrades. 


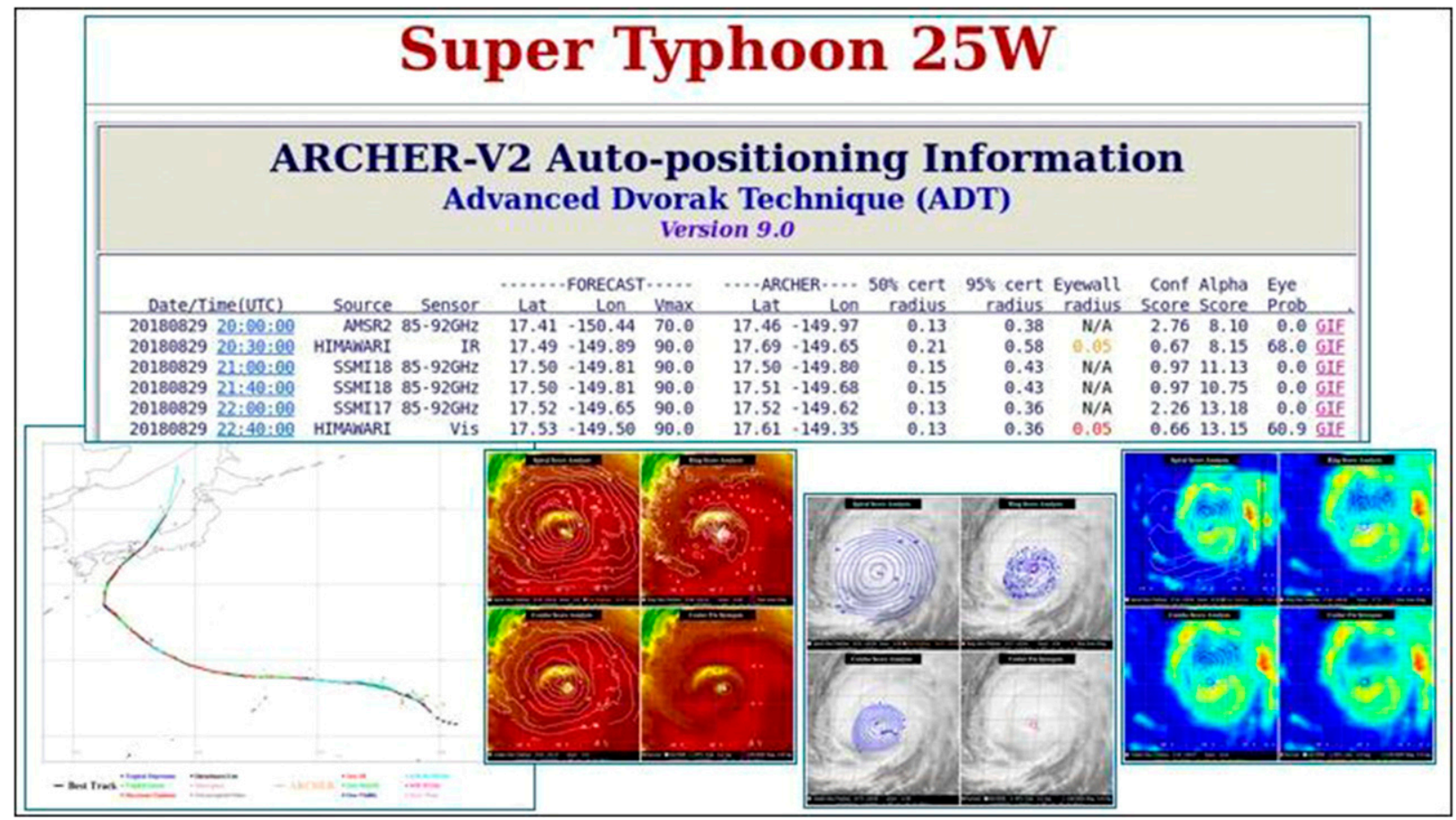

FIG. 5. Typical real-time output displays from ARCHER-2, including diagnostics and a history of each analysis time for an entire storm, graphical displays, and ARCHER-2 storm positions relative to best track.

\section{a. ARCHER-2 storm-center determination}

A significant enhancement to the ADT version 9 algorithm is the implementation of the Automated Rotational Center Hurricane Eye Retrieval (ARCHER) TC objective storm center determination scheme, ARCHER-2. The ARCHER-2 algorithm (Wimmers and Velden 2016) replaces the previous automated storm center determination scheme utilized in ADT version 7 and outlined in Olander and Velden (2007). The ARCHER-2 analysis is run separately and prior to the actual ADT processing, with its analysis information being passed into the ADT executable. The analysis components include ring-fitting, spiral centering, and combination field analysis, and ARCHER-2 utilizes multispectral satellite imagery to determine and select the most confident storm center positions. Geostationary satellite longwave IR, shortwave IR, and visible (when available) imagery are analyzed along with 85-91- and 37-GHz PMW imagery to determine the current TC center position. Scatterometer ambiguity fields can also be used but are not yet tested in ADT version 9. Delayed PMW imagery-derived positions are still considered in the current position analysis by extrapolating them to the current analysis time using a storm motion vector obtained from the OpCen forecast, with a time-weighted reduction of the corresponding confidence score. The image with the highest confidence score value is used as the current position of the storm.

The ARCHER-2 algorithm is run just prior to the execution of the ADT (operationally this is every $30 \mathrm{~min}$ ), with the best-estimate storm center position passed into the ADT along with the position confidence score also derived by the ARCHER-2 algorithm. UNIX shell scripts controlling the ARCHER-2 position determination process can also derive various output graphical and textual ARCHER-2 analysis products for further interrogation, if desired.

A final check is performed within the ADT script to only utilize ARCHER-2 positions which exceed an empirically determined threshold value for the input confidence scores. This threshold value is basin specific, with stricter values for basins that are frequented by reconnaissance aircraft fixes. If the center-fix analysis confidence score value is below the threshold value, an interpolated OpCen forecast position is used as the default position by the ADT.

Figure 5 shows many of the output display options generated by the ADT ARCHER-2 processing package. Included in these displays are history file-type listings of each ARCHER-2 analysis associated with every ADT run. Within each line, analysis output for each type of image examined is also generated, including the final confidence factors, along with a graphical output display 
corresponding to the selected image for that particular analysis. A display of the resulting ARCHER-2 track compared to the current best track is also generated to facilitate real-time interrogation of the position estimates that the ADT is using to obtain its intensity estimates.

\section{b. Extratropical transition analysis}

After Manion et al. (2015) documented a general weak bias in ADT intensity estimates for TCs undergoing extratropical transition (ET), an adjustment was developed and implemented into version 9. The correction is based on simple basin-specific regression equations that are applied to the ADT CI\# as follows:

$$
\begin{aligned}
& \text { Atlantic/east }- \text { central Pacific : ET_Wind_Correction } \\
& \quad=-0.57 \times \mathrm{WCI}+30.0(\mathrm{kt}),
\end{aligned}
$$

Other basins: ET_Wind_Correction

$$
=-0.70 \times \mathrm{WCI}+30.0(\mathrm{kt}),
$$

$\mathrm{WCI}=$ wind speed converted from the current

\section{ADT CI\#,}

with the final ADT CI\# $=($ WCI + ET_Wind_Correction) converted back to CI\#.

The ET adjustment technique basically relies upon the Florida State University Cyclone phase space (Hart 2003) product operating from the GFS model analysis and forecast parameters to identify the onset of ET. Real-time analysis plots (and detailed explanation of the phase space product) are available at http:// moe.met.fsu.edu/cyclonephase/gfs/fcst/index.html. An operational version of this product with needed parameters for the ADT is also available from NCEP. ET onset is defined when the current and 6-h previous phase space "beta" values both exceed 10.0 and the storm is poleward of $20^{\circ} \mathrm{N} / 15^{\circ} \mathrm{S}$ latitude. The ET onset check is performed prior to the ADT execution and the flag is stored in an external file, with the flag and current beta value passed into the ADT algorithm. Once these criteria are met, at any point in the storm history, the ET flag can be triggered. However, additional criteria must also be met during the ADT execution for the ET adjustment to be applied. First, the storm cannot be within $24 \mathrm{~h}$ of a PMW adjustment. Also, the percentage of shear scenes in the previous $12 \mathrm{~h}$, stored in the ADT history file, must be greater or equal to $50 \%$. If these criteria are satisfied, the ET adjustment will then be applied. Both of these rules are utilized to try and assure the storm is in the nonformative phase of its life cycle and transitioning toward a more nontropical, midlatitude type of storm. The ADT will typically assign the SHEAR scene type to late life cycle, baroclinic-enhanced storms, since the low-level center position is usually separated from the convective cloud regions. The PMW rule assures there are no conflicting ET and PMW adjustments being applied to the CI\# intensity values.

As with the PMW eye score adjustment, once the ET adjustment is initiated, the CI\# values stored in the ADT history file are modified by linearly interpolating between the current (newly ET-adjusted) CI\# and the 12-h previous CI\# values. This step helps to avoid potential unnatural jumps in the CI\# values at the onset of the ET adjustment. Once the ET adjustment is triggered, it will continue to be applied for the remainder of the storm life cycle until OpCen bulletins are discontinued, since it is incredibly rare for storms to transition from ET (back) to tropical.

Figure 6 shows a typical example of an ET adjustment, where an attempt is made to correct for the ADT weak bias noted in Manion et al. (2015). Western Pacific TC Maliksi (2018) underwent ET which began on 11 June. The ADT ET flag tripped about 1200 UTC on that day, and following the ET rules described above the previous $12 \mathrm{~h}$ of ADT CI\# values were modified back to around 0000 UTC. The unadjusted ADT version exhibits a strong weak intensity bias versus the JTWC best track during the ET event, and the ET intensity adjustment corrects the final ADT estimate toward the best track.

\section{c. Subtropical storm analysis}

Expansion of the ADT to perform analyses on systems designated as subtropical (ST) was undertaken in direct response to user feedback, and is initiated when a TC OpCen designates a storm as a subtropical depression or storm within the ATCF best track files using the "SD" or "SS" designators, respectively. The ADT ST analysis scheme is only applied and an intensity adjustment made when the diagnosed ADT scene type is curved band. Shear scene types are not allowed under these conditions and are reassigned to curved band scene types in order to properly apply the ST adjustment scheme defined below. All other scene types are analyzed as normal without any ST intensity adjustment.

The ST analysis scheme performs on a modified ADT curved band scene type temperature range which normally begins with the Dvorak enhanced IR "BD curve dark gray" (from $-30^{\circ}$ to $-42^{\circ} \mathrm{C}$ ) temperature range, but is extended to include the range from $-10^{\circ}$ to $-30^{\circ} \mathrm{C}$. This added temperature range increases the spatial size and coherency of the storm cloud pattern being examined since the convective cloud top temperatures in ST systems are typically broader and warmer 


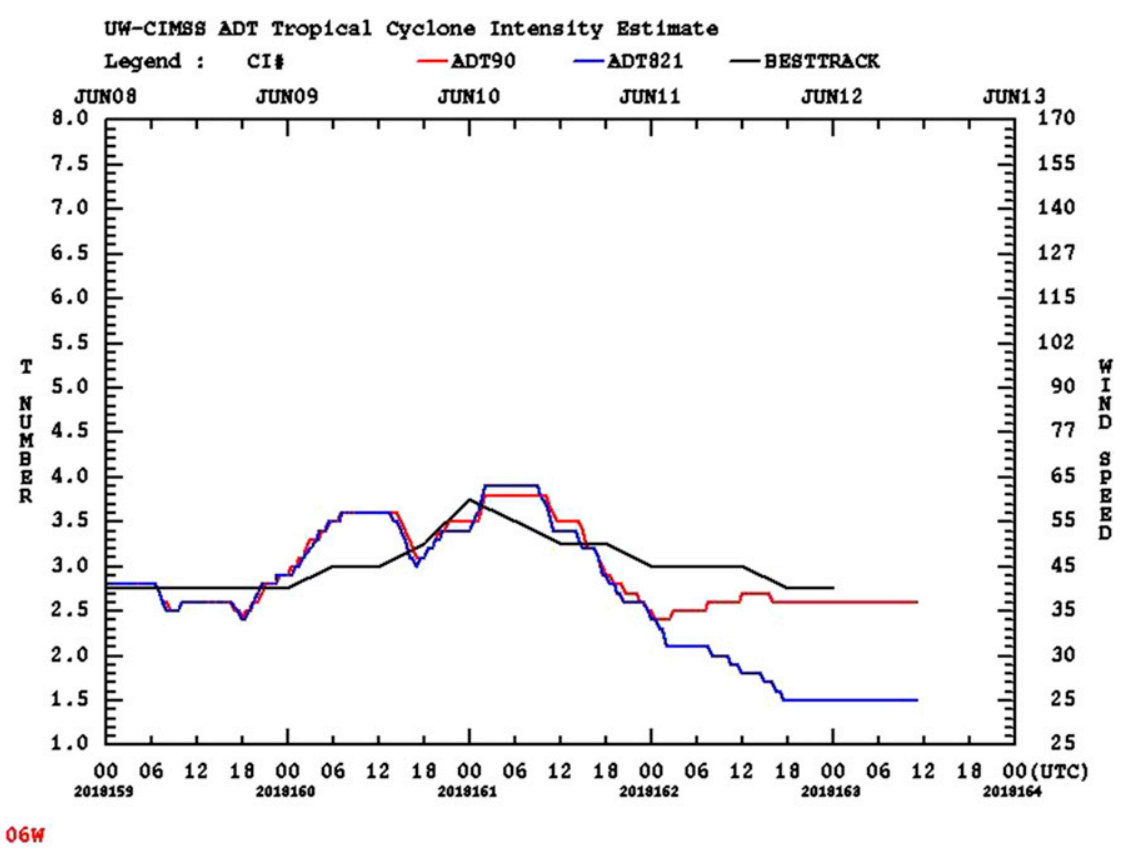

FIG. 6. Intensity traces (Vmax; kt) for Tropical Cyclone Maliksi (2018) undergoing ET. The red (blue) curve indicates the ADT with (without) the ET adjustment. The black curve is the JTWC best track.

than tropical systems. The new temperature range is highlighted with a blue shading in the example enhanced IR BD curve plots shown in Fig. 7 (and displayed on the ADT analysis webpages).
Utilization of the ST scheme results in improved ADT intensity estimates for subtropical systems; however, it was found empirically by comparing to operational best track (BT) intensity estimates of Vmax that a small

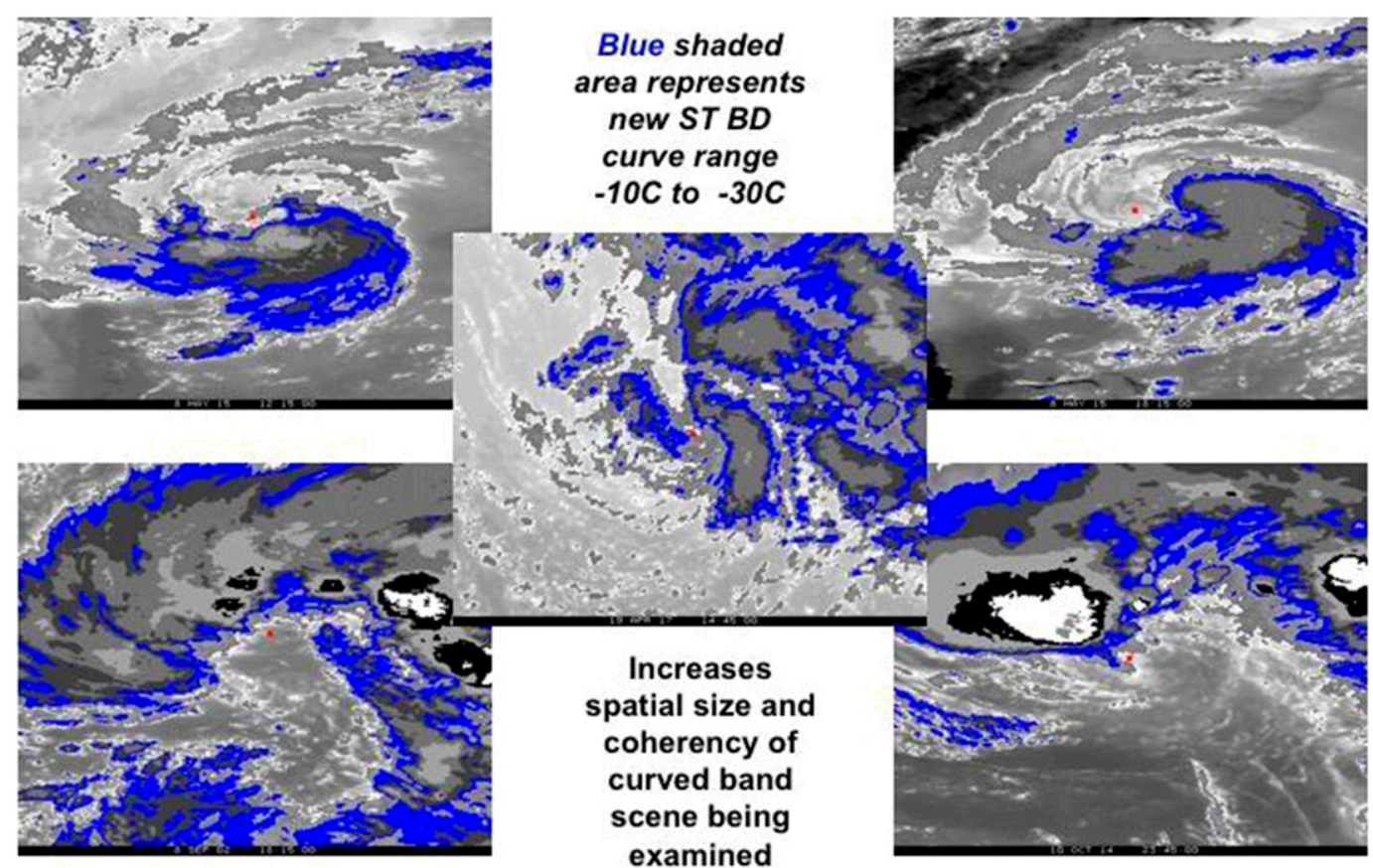

FIG. 7. Examples of the modified BD enhancement temperature range utilized by the ADT algorithm to perform curved band analysis in designated subtropical systems. 
TABLE 1. Impact of ADT subtropical (ST) adjustment validated against NHC best track (with aircraft within $3 \mathrm{~h}$ ) based on 66 comparisons in Atlantic subtropical storms from 2000 to 2015. OpCen Dvorak estimates were averaged if coincident multiple reports available.

\begin{tabular}{lrcc}
\hline \multicolumn{1}{c}{ Vmax (kt) } & Bias & Absolute error & RMSE \\
\hline ADT without STadj & -12.1 & 12.1 & 13.7 \\
ADT with STadj & -1.4 & 5.4 & 6.5 \\
OpCen Dvorak & -1.5 & 4.7 & 6.2 \\
\hline
\end{tabular}

weak bias of around $5 \mathrm{kt}$ still existed. Therefore, an additional +5 -kt bias adjustment is applied to the ST intensity analysis estimates to provide the final ADT intensity estimate. Table 1 shows the significant improvement garnered by the application of the ST adjustment versus the ADT not using the ST adjustment, and comparisons with OpCen Dvorak technique intensity estimates. Figure 8 shows an example of the impact of the ST adjustment on the ADT for Subtropical Storm Alberto (01L) in the North Atlantic in 2018.

\section{d. Surface wind radii estimates}

In addition to TC intensity measurements such as Vmax and MSLP, the outer vortex surface wind radii are important in determining the extent and influence a storm can have, such as the onset of hazardous conditions and storm surge. Therefore, an enhancement was added to ADT version 9 that includes satellite-based estimates of the 34-, 50-, and 64-kt wind speed radii in the four storm quadrants (NE, NW, SE, and SW). This technique was developed by John Knaff (NOAA/ NESDIS/RAMMB) and is competitive with other radii estimates as documented in Knaff et al. (2016). Implemented into the ADT, the algorithm starts with the estimated Vmax derived by the ADT and the current storm motion vector information derived from the basin-respective OpCen working best track file. An estimate of the storm radius of maximum wind (RMW) is also needed and is either retrieved from the ADT or a climatological value is used if the ADT is unable to derive the value. The technique will then use IR image brightness temperature information to estimate the wind speed radii in the four quadrants. The resulting wind radii estimates can then be output within the normal ADT processing textual output or used to derive graphical displays as shown in Fig. 9.

\section{e. Other notable modifications}

ADT version 9 includes code and operability modifications to properly utilize the improved spatial and temporal resolutions provided by the latest geostationary satellites such as the Meteosat-Second Generation series, the Himawari series, and the GOES-R series. Most of the ADT methodologies during algorithm development assumed 4-km and 30-min IR imagery, which

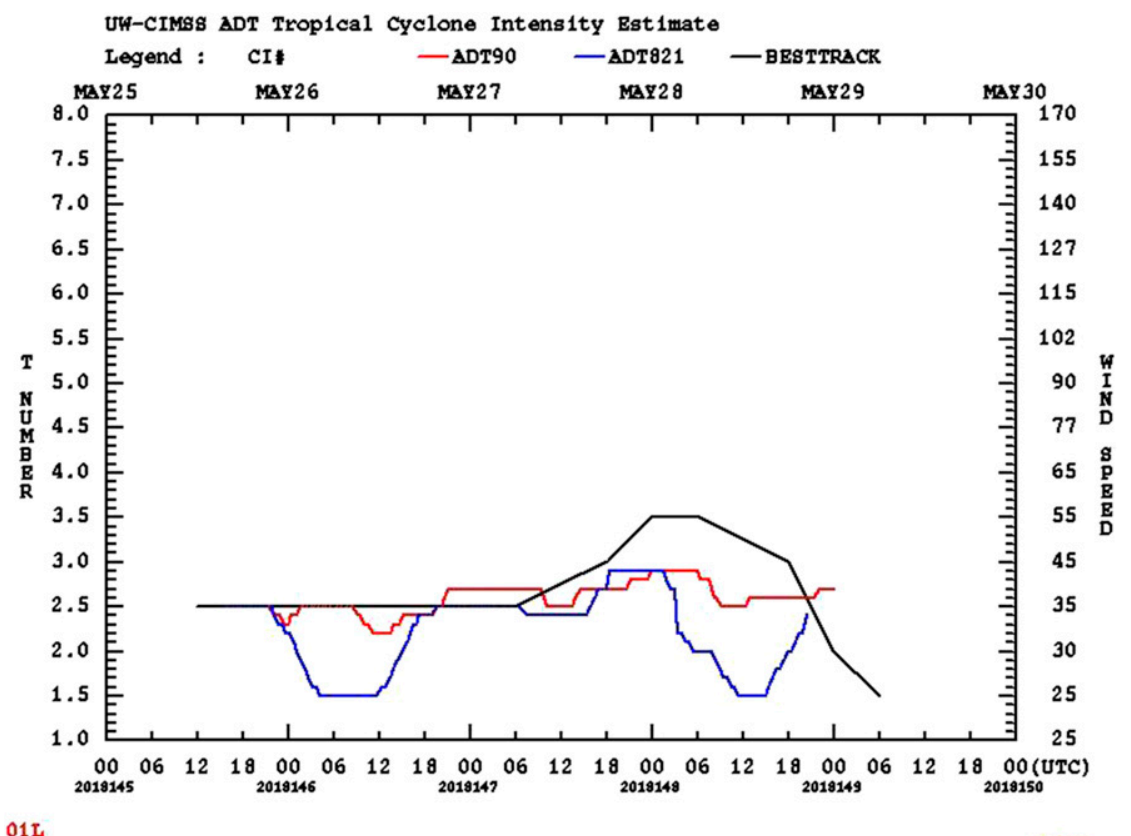

FIG. 8. ADT intensity plots (Vmax; kt) for Alberto (01L) in 2018, classified as subtropical by NHC for the entire history of the storm. ADT version 9 (red) includes the ST intensity adjustment. The black line is the NHC best track. 


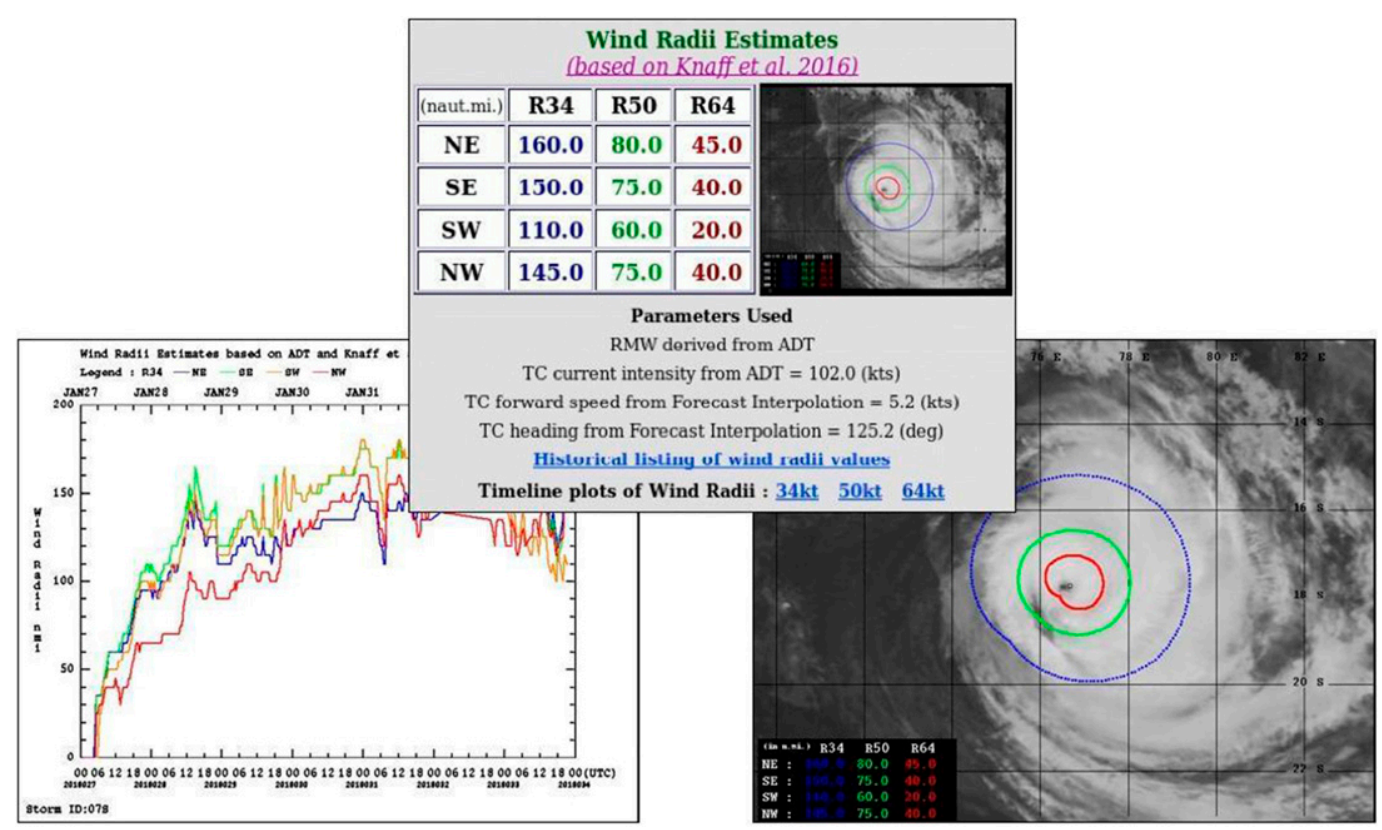

FIG. 9. Examples of ADT output of estimated outer vortex surface wind radii (table, plot, and storm history for radii in each quadrant).

has been upgraded to $2 \mathrm{~km}$ and more frequent sampling availability for most of the recently launched operational geostationary satellites. In addition to assuring functionality, experiments were designed to assess the impact on ADT intensity analyses using the increased spatiotemporal sampling available with these new satellites.

The improved spatial resolution was tested by comparing ADT estimates for TCs that occurred during the transition of the new satellites to operational status. During these periods, the satellite being replaced was still producing imagery while the new generation satellite was being commissioned and also producing imagery. Using coincident imagery from both satellites (e.g., MTSAT and Himawari-8; GOES13 and GOES-16) and choosing TC cases when the relative scan angles were close, the ADT results were compared. A short internal study comparing simultaneous 4-km GOES-13 and 2-km GOES-16 data with recon-aided NHC BT during the 2017 North Atlantic season found small overall impact on Vmax estimates (bias and RMSE differences less than $1 \mathrm{kt}$ ). There are occasional situations when the CI\# deviates by up to 0.5 , mainly in cases when the 2-km imagery is a little quicker in resolving a small eye scene. While this could potentially briefly impact a particular storm, the overall impact on the ADT performance did not support a generalized intensity adjustment for higher spatial resolution imagery. This finding was confirmed by an analysis done in 2015 by the Japan Meteorological
Agency (JMA), comparing the results from 4-km MTSAT with 2-km Himawari-8 on their manual Dvorak intensity estimates (Koide 2016). Overall differences were less than 0.1 CI\#, with occasional maximum differences during a storm of 0.5 .

Utilization of higher temporal resolution imagery was also tested and shown to have limited impact upon the ADT results. During the 2015 west Pacific and Southern Hemisphere TC seasons, 22 storms were examined using 10- and 30-min data from Himawari-8. The comparison showed that while some minor deviations in the CI\# values were observed using the two sampling intervals (Olander and Velden 2016), the overall CI\# difference was just 0.01 from the approximately 7300 matching records versus JTWC best track. Based on this, the 30-min analysis is retained and recommended for operational use.

Another notable ADT modification involves a tweak to the eye regression equations stemming from a study to identify and reanalyze extremely intense TCs using the ADT (Velden et al. 2017). By comparing to aircraftmeasured intensities and OpCen BTs, the study resulted in two specific changes that address an observed ADT weak bias at these extreme intensities $(C I \geq 7.0)$. First, a $+0.1(+0.3)$ adjustment to the Atlantic/east Pacific (northwest Pacific) regression equation is implemented when a storm ADT T\# value is $\geq 7.0$. Second, for storms located in the Indian Ocean and Southern Hemisphere, the ADT will utilize the original, nonadjusted northwest Pacific eye regression equations 
TABLE 2. Homogeneous comparison between ADT and OpCen Dvorak estimates of Atlantic TC intensity in 2018 validated against reconnaissance aircraft-aided NHC best track for $\mathrm{Vmax}(\mathrm{kt})$ and $\operatorname{MSLP}(\mathrm{hPa})$.

\begin{tabular}{lrcr}
\hline \hline \multicolumn{1}{c}{$N=73$} & Bias & Absolute error & RMSE \\
\hline ADT - Vmax & -4.41 & 8.85 & 11.12 \\
OpCen - Vmax & -1.79 & 7.08 & 10.40 \\
ADT - MSLP & 0.02 & 6.67 & 9.71 \\
OpCen - MSLP & -2.80 & 5.97 & 10.17 \\
\hline
\end{tabular}

since storms in these basins did not exhibit any significant weak intensity bias in the Velden et al. (2017) study.

\section{ADT version 9 validation}

To assess the ADT intensity estimates and version 9 algorithm performance, a real-time global validation was performed during 2018. In the statistical analysis presented below, the ADT objective intensity estimates are compared to OpCen BT intensity estimates from NOAA/NHC or JTWC (depending on TC basin), and operational manual Dvorak estimates from various OpCens worldwide. The OpCen "working" (real-time) BT files were utilized in this study since they more closely mirror what would be available operationally during storm events. If there are multiple OpCen Dvorak estimates available at a given time, the CI\#s are averaged to create a "consensus" value, which is then converted to 1-min Vmax and MSLP estimates.

In the North Atlantic basin, ADT intensity estimates and OpCen Dvorak estimates from the NHC/ Tropical Analysis Forecast Branch (TAFB) and NOAA/ NESDIS/Satellite Analysis Branch (SAB) were compared to the operational (ATCF) BT data from NHC available every 6 hours on the synoptic times $(0000,0600,1200$, and 1800 UTC). OpCen Dvorak estimates are also typically produced every $6 \mathrm{~h}$ on the synoptic times but can be produced at nonsynoptic times as well. An additional criterion is imposed for the comparisons in this basin to take advantage of in situ aircraft reconnaissance measurements of intensity: all concurrent estimates (ADT and OpCen) must be within $1 \mathrm{~h}$ of each other, and within $3 \mathrm{~h}$ of a recon intensity measurement.

Outside of the North Atlantic TC basin, where aircraft reconnaissance is generally scarce or not available, the $\mathrm{ADT}$ and OpCen Dvorak intensity estimates are compared to the ATCF working BT files from the NHC (eastern Pacific), CPHC (central Pacific) or JTWC (elsewhere). In some of these other TC basins, the OpCen subjective Dvorak estimates are often produced up to $2.5 \mathrm{~h}$ off the synoptic times. Therefore, the match criteria was
TABLE 3. Homogeneous comparison between ADT and OpCen Dvorak estimates of east-central Pacific TC intensity in 2018 validated against the nonreconnaissance aircraft-aided best tracks from NHC (east Pacific) and CPHC (central Pacific) for Vmax (kt) and MSLP $(\mathrm{hPa})$.

\begin{tabular}{lrcc}
\hline \hline \multicolumn{1}{c}{$N=552$} & \multicolumn{1}{c}{ Bias } & Absolute error & RMSE \\
\hline ADT - Vmax & -0.87 & 7.11 & 9.18 \\
OpCen - Vmax & 0.99 & 8.48 & 9.71 \\
ADT - MSLP & -1.86 & 5.16 & 6.78 \\
OpCen - MSLP & -2.68 & 6.84 & 7.13 \\
\hline
\end{tabular}

increased to $\leq 3 \mathrm{~h}$ to provide significantly more homogeneous comparisons.

As shown in Table 2, the ADT generally compares well to the matching OpCen Dvorak estimates for the 73 Atlantic cases during 2018. A notable exception is the Vmax, where a significant ADT weak bias is found versus the BT. This tendency has been noted in recent years with NHC's increased use of the airborne stepped frequency microwave radiometer (SFMR) for surface wind speed estimates in their BTs. SFMR estimates of Vmax are sometimes found to be higher (Klotz and Uhlhorn 2014), especially in weaker intensity classifications or when the rain rates within the beam are high, than what would be estimated using traditional flight-level-wind-reduction practices (on which the ADT was trained and tuned during development). NHC has also noted an SFMR bias in some of their official tropical cyclone reports, notably Irma (Cangialosi et al. 2018) and Jose in 2017 (Berg 2018). The OpCen Dvorak Vmax also has a negative bias (the highest of any basin), but not quite as high as the ADT. Curiously, the ADT weak bias is not observed in MSLP; however, this could be partially the result of the CKZ methodology discussed in section $2 \mathrm{~b}$. It is beyond the scope of this paper to further address this issue, but it is interesting that an ADT Vmax bias of this magnitude is not found in any other basin. If the SFMR speed values for Vmax are verified and continue to produce higher Vmax BT intensities, the ADT may need to be recalibrated.

In other TC basins, the ADT compares favorably with the operational Dvorak intensity estimates, and in many cases is notably better. This is despite the fact that the BTs are heavily influenced by the operational Dvorak intensities, as in most cases of TCs outside of the Atlantic, satellite-based estimates are all that are available. It should be noted that the ADT estimates may also now be influencing OpCen BTs since the ADT has gained some acceptance with most global TC OpCens. To what degree is not known or documented, but direct comparisons between ADT and OpCen Dvorak estimates are likely less contaminated. Validation statistics for four other TC basins are shown in Tables 3-6. The ADT MSLP errors are generally lower than the OpCen errors, supporting the 
TABLE 4. As in Table 2, but for the western North Pacific and validated against the best tracks from JTWC for Vmax (kt) and $\operatorname{MSLP}(\mathrm{hPa})$.

\begin{tabular}{lccr}
\hline \hline \multicolumn{1}{c}{$N=712$} & Bias & Absolute error & RMSE \\
\hline ADT - Vmax & -1.25 & 8.67 & 11.24 \\
OpCen - Vmax & -0.50 & 9.12 & 11.19 \\
ADT - MSLP & 2.33 & 6.02 & 8.43 \\
OpCen - MSLP & -2.13 & 9.54 & 10.80 \\
\hline
\end{tabular}

implementation of the CKZ wind-pressure relationship into the ADT algorithm.

To illustrate the ADT's situational performance behavior, intensity estimates for the life cycles of selected storms from 2018 are presented. The first few cases (Figs. 10-13) highlight examples of the ADT doing a reasonably good job compared with BTs, followed by some challenging examples (Figs. 14-16). A short discussion of each case is provided to highlight the ADT attributes.

Hurricane Florence was a significant North Atlantic TC that caused severe damage along the eastern U.S. seaboard during and after landfall. Florence was notable for two periods of rapid intensification followed by rapid weakening, making it a challenging case for intensity estimation. Florence also had frequent aircraft-collected intensity observations from 1700 UTC 8 September to 1200 UTC 14 September, thereby providing solid verification. The ADT compares reasonably well with the NHC BT for the first major intensity fluctuation (Fig. 10), but then deviates on the weak side for a couple of days as Florence encountered strong southwesterly shear between 0900 UTC 6 September and 0900 UTC 8 September, partially exposing the lowlevel circulation, decreasing convection, and warming the cloud tops. ADT scene types changed too quickly from eye to curved band and shear, resulting in this weak bias period as verified by recon observations. After the shear period abates, the ADT recovers and catches up with the second period of rapid intensification, it does quite well in estimating the peak intensity and following weakening trend. Statistically, the ADT bias (negative) was larger than the OpCen Dvorak for this storm, but the mean error and RMSE were close to or better than the OpCen values despite the midstorm overweakening.

Hurricane Aletta was an east Pacific TC that peaked near $120 \mathrm{kt}$ (NHC BT). As shown in Fig. 11, the ADT peaks about $5 \mathrm{kt}$ higher, but generally captures the rates of intensification and weakening. A PMW adjustment was utilized on 7 June, which results in a close match with the NHC BT. While no recon reports are available for this storm, the ADT performance statistics compared to the BT are slightly better than the OpCen Dvorak estimates.
TABLE 5. As in Table 4, but for the north and south Indian Ocean for $\operatorname{Vmax}(\mathrm{kt})$ and MSLP $(\mathrm{hPa})$.

\begin{tabular}{lccr}
\hline \hline \multicolumn{1}{c}{$N=78$} & Bias & Absolute error & RMSE \\
\hline ADT - Vmax & 2.13 & 8.31 & 10.35 \\
OpCen - Vmax & 1.19 & 10.09 & 10.27 \\
ADT - MSLP & 2.86 & 5.75 & 6.99 \\
OpCen - MSLP & -1.73 & 5.46 & 6.67 \\
\hline
\end{tabular}

Typhoon Soulik was a western North Pacific TC that exhibited a well-behaved intensity trace over its lifetime, with a period of steady deepening, then several days at steady state, followed by gradual weakening. As might be anticipated for a storm without dramatic intensity fluctuations, the ADT performs reasonably well overall (Fig. 12). However, it is interesting to note the considerable amount of spread in the OpCen Dvorak estimates, especially from 17 to 19 August, when the differences are as high as $1.0 \mathrm{CI \# .} \mathrm{This} \mathrm{case} \mathrm{highlights} \mathrm{some}$ of the interagency subjectivity with the manual Dvorak technique that can manifest due to differences in image interpretation (i.e., clear vs ragged eye) and subsequent rules application. In an unusual fashion near the tail end of the storm, the JTWC BT actually changed the storm designation from tropical to subtropical to extratropical over the period from 1200 UTC 24 August to 0000 UTC 25 August. The ADT ST flag did not trip but the ET adjustment went on at 0200 UTC 24 August, bringing the intensity more in line with the BT.

Super Typhoon Yutu was a western North Pacific TC storm memorable for its late-season peak intensity near $155 \mathrm{kt}$ (JTWC BT), and a 130-kt increase in Vmax over just $72 \mathrm{~h}$. Despite these challenging intensity metrics, the ADT (and the OpCen Dvorak) nails both (Fig. 13). More variability develops after this time, but the general BT weakening trend is well captured. It is difficult to assess the short-term fluctuations in the ADT estimates without recon verification, but the OpCen trends are inherently smoother.

Atlantic Hurricane Helene is a challenging case because it shows the importance of the PMW analysis scheme and how the ADT intensity can plateau when it is locked into a CDO scene type (Fig. 14). There was only one PMW overpass on 9 September, and it yielded a

TABLE 6. As in Table 4, but for the South Pacific for Vmax (kt) and $\operatorname{MSLP}(\mathrm{hPa})$.

\begin{tabular}{lrcr}
\hline \multicolumn{1}{c}{$N=389$} & \multicolumn{1}{c}{ Bias } & Absolute error & RMSE \\
\hline ADT - Vmax & -0.81 & 8.75 & 12.18 \\
OpCen - Vmax & 0.33 & 8.81 & 12.08 \\
ADT - MSLP & 1.92 & 6.44 & 8.97 \\
OpCen - MSLP & -4.87 & 8.58 & 10.20 \\
\hline
\end{tabular}




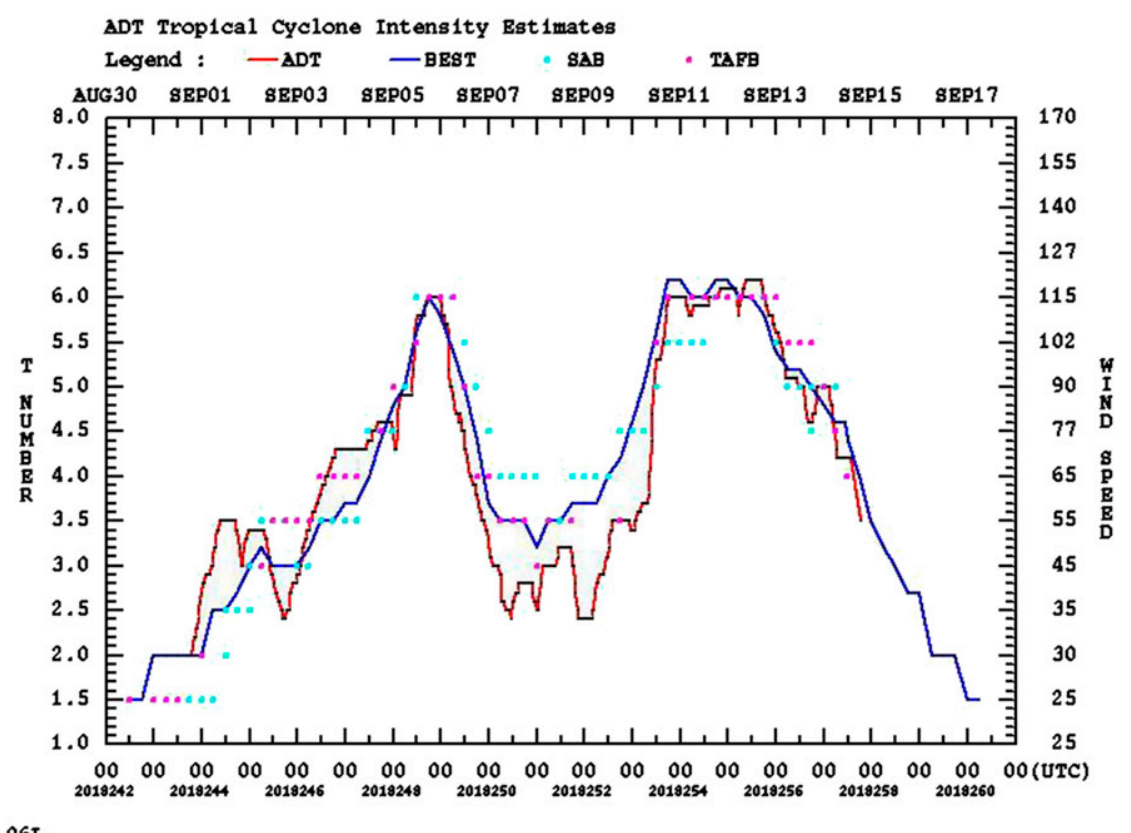

06L

FIG. 10. ADT Vmax (kt) estimates (red) compared with NHC best track (blue) and operational Dvorak estimates from SAB and NHC/TAFB for Hurricane Florence (06L) in 2018.

score that was just below the PMW-triggering threshold. If that score would have been just a bit higher, the ADT intensities would have matched quite well with the NHC BT since the ADT intensity would have increased to around CI\# 4.3, very near the BT intensity at this time (not shown). Such can be the fickle nature of empirically based, threshold-dependent schemes. Early on
10 September, the ADT finally diagnoses an eye scene in the IR imagery, the emergence of which was more easily resolved by human analysts. Thus, the OpCen Dvorak estimates exhibit a steady intensification and no intensity plateau. Objective eye detection (in IR imagery) is one area that needs further attention in the ADT algorithm.

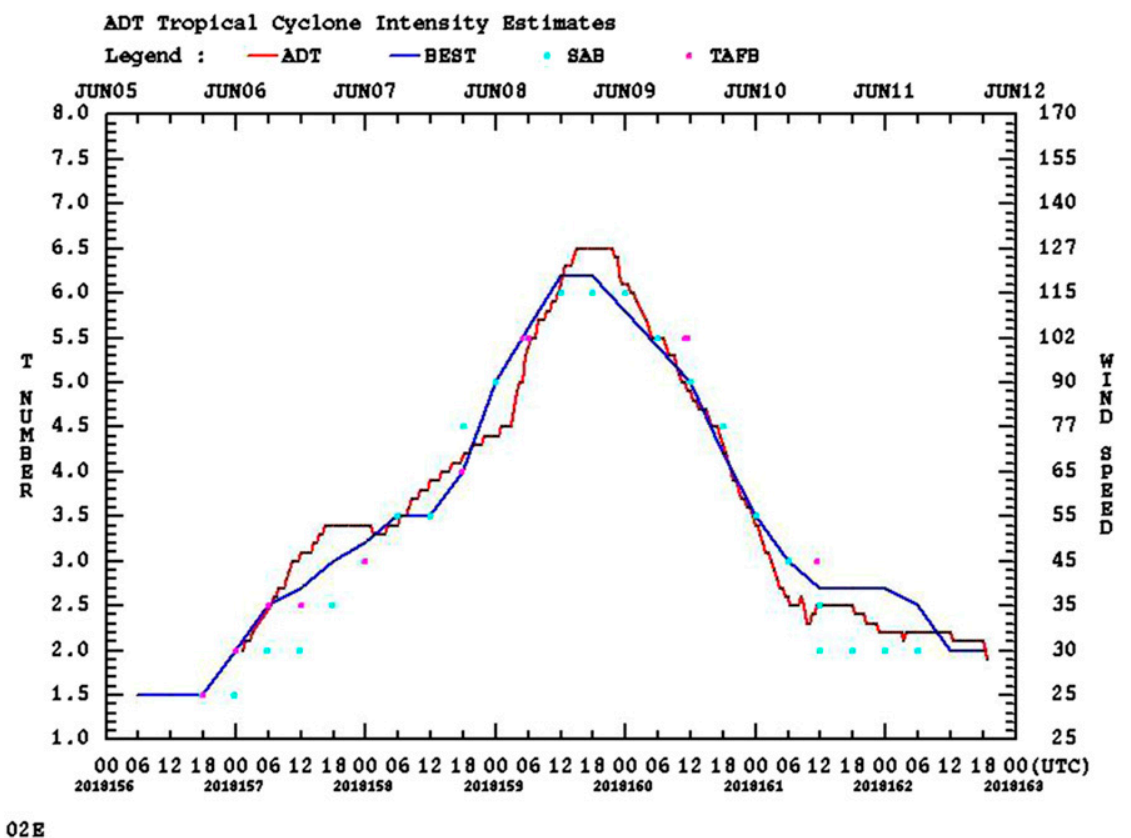

FIG. 11. As in Fig. 10, but for Hurricane Aletta (02E) in 2018. 


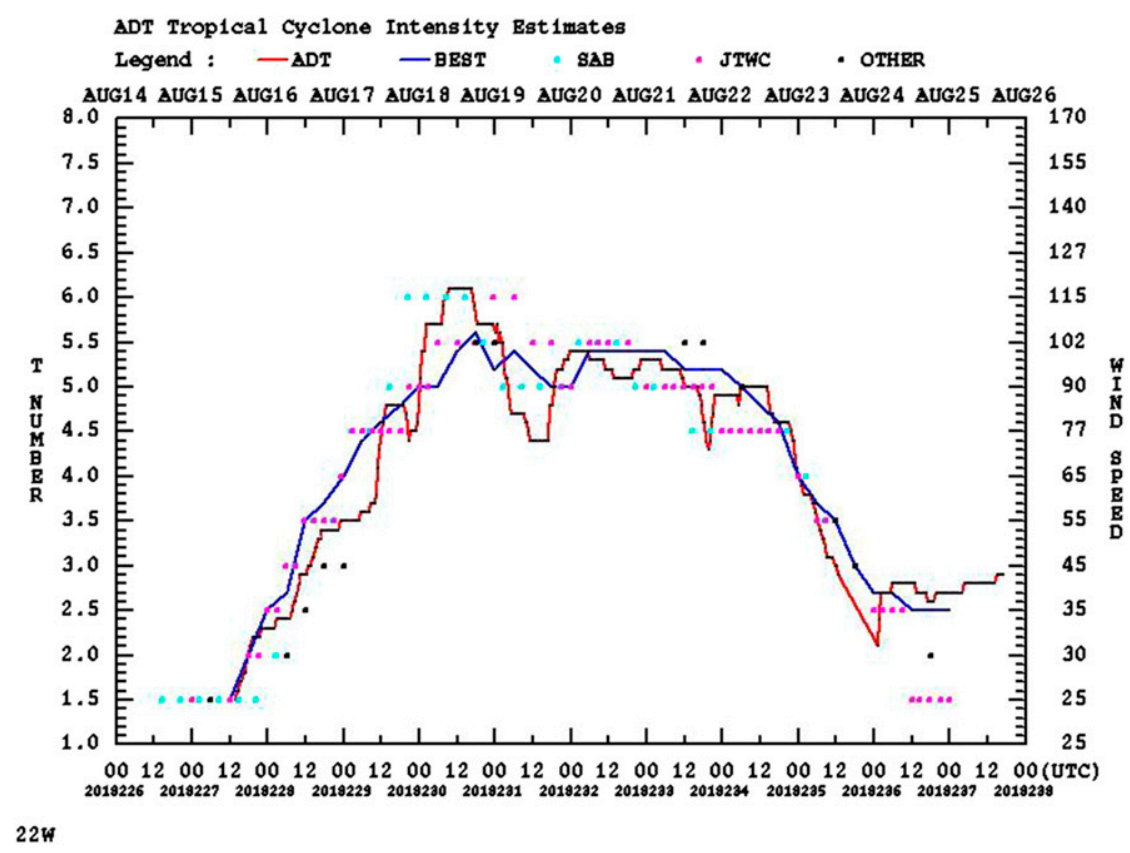

FIG. 12. ADT Vmax (kt) estimates (red) compared with JTWC best track (blue) and operational Dvorak estimates from SAB, JTWC, and Japan Meteorological Agency for Typhoon Soulik (22W) in 2018.

Hurricane Sergio was an east Pacific TC where the ADT compares fairly well with the NHC best track and the OpCen Dvorak estimates (Fig. 15) until 9 October when the storm was weakening over cooler waters. The ADT rapidly weakens the TC while the OpCen Dvorak estimates remain higher. While there was no recon in this storm, scatterometer data support the higher estimates. In this case the Dvorak rules for decaying intensity worked better than the ADT relaxed constraints. However, past cases in this basin with strong SST gradients warranted the

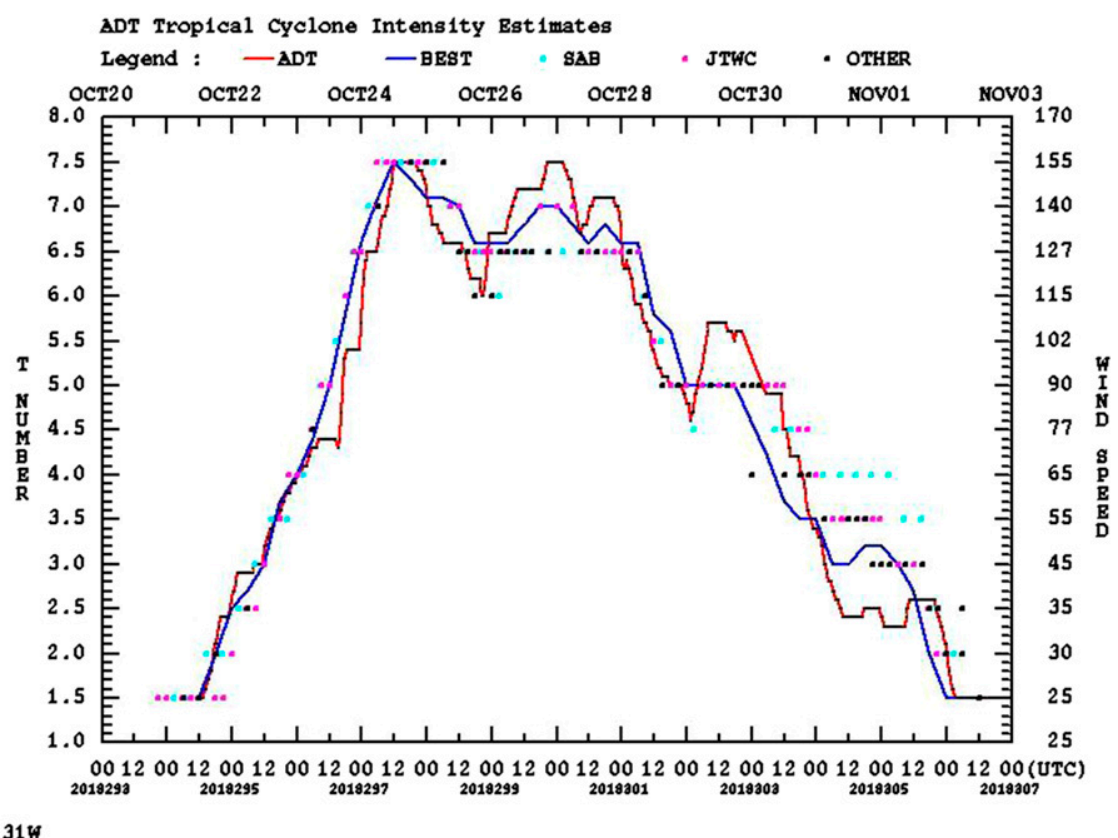

FIG. 13. As in Fig. 12, but for Super Typhoon Yutu (31W) in 2018. 


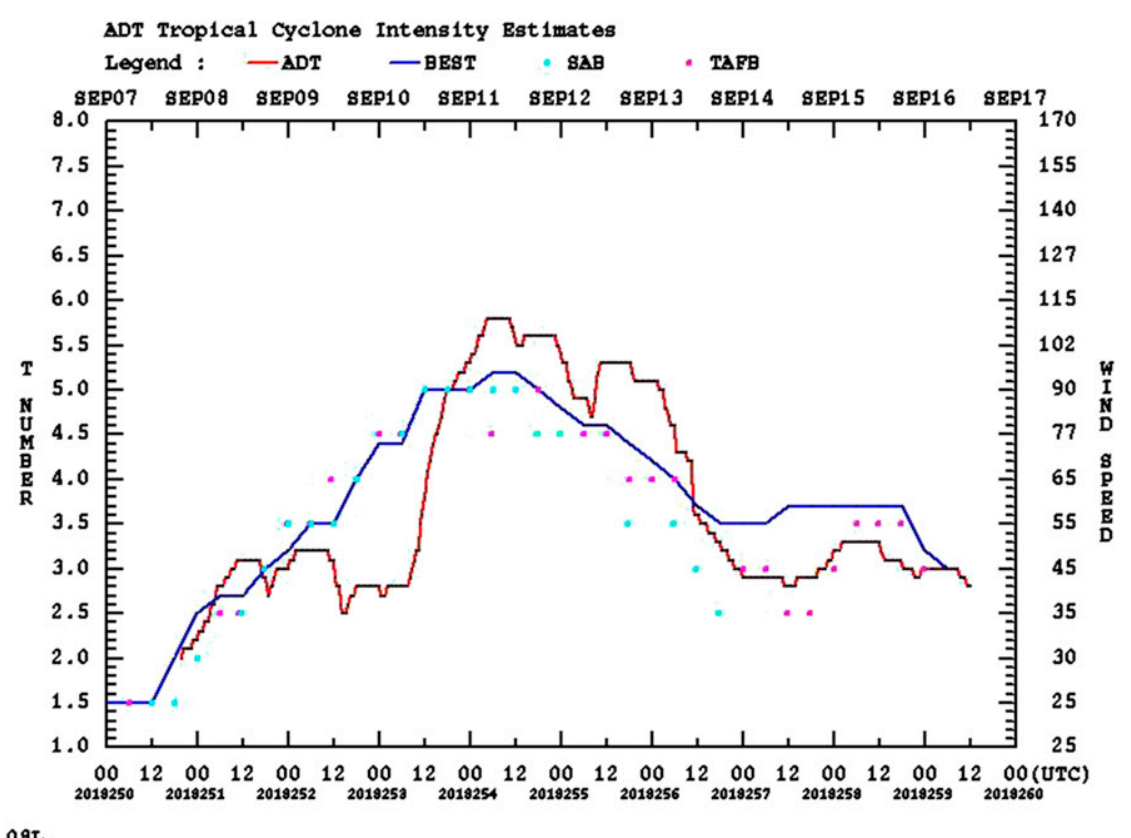

FIG. 14. As in Fig. 10, except for Hurricane Helene (08L) in 2018.

implement of a quicker intensity response to a waning convective signal. Further investigations focusing on weakening stages are needed.

Severe Tropical Cyclone Marcus was a very powerful TC that struck Australia's Northern Territory and the Kimberley region of Western Australia. Marcus was a challenging storm for the ADT mainly due to a loss of PMW data during a period when the storm was forming a small IR eye. Figure 16 shows that the ADT nicely captures the initial emergence of the eye and rapid intensification early on 19 March. However, by around 1200 UTC the eye becomes too small/indistinct to be analyzed by the ADT objective methodology, and the ADT scene types change to $\mathrm{CDO}$ and embedded center until

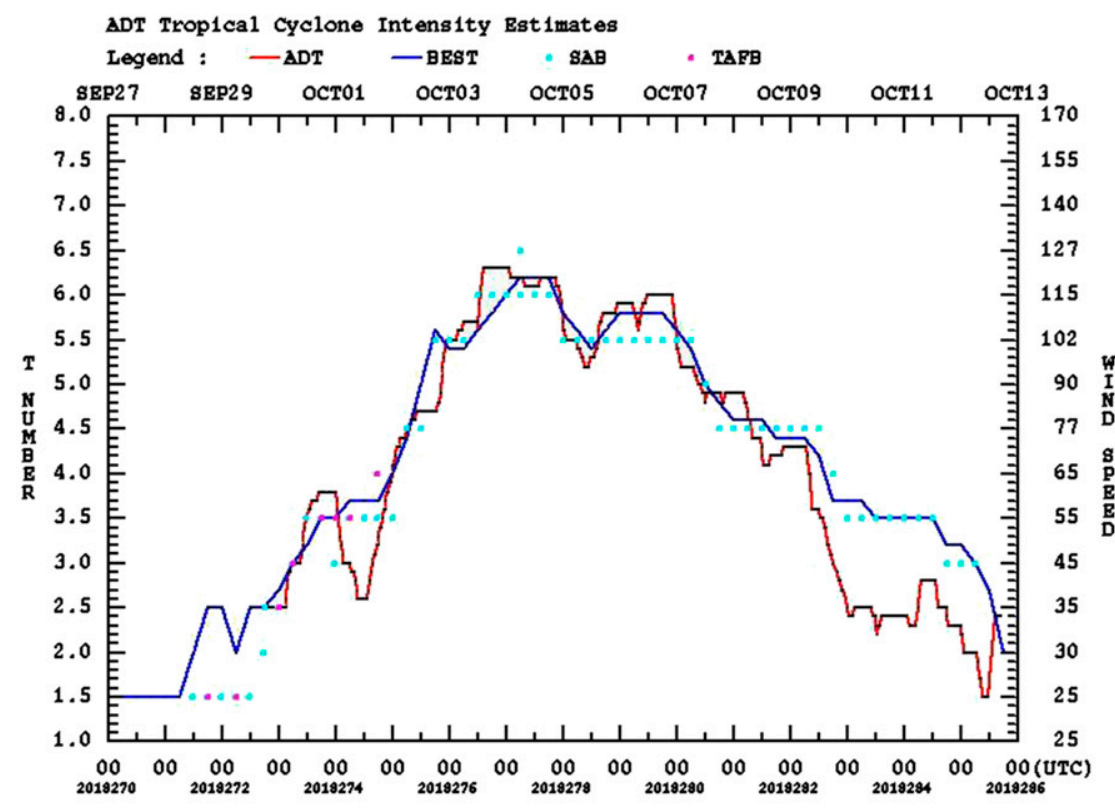

$21 \mathrm{~B}$

FIG. 15. As in Fig. 11, but for Hurricane Sergio (21E) in 2018. 


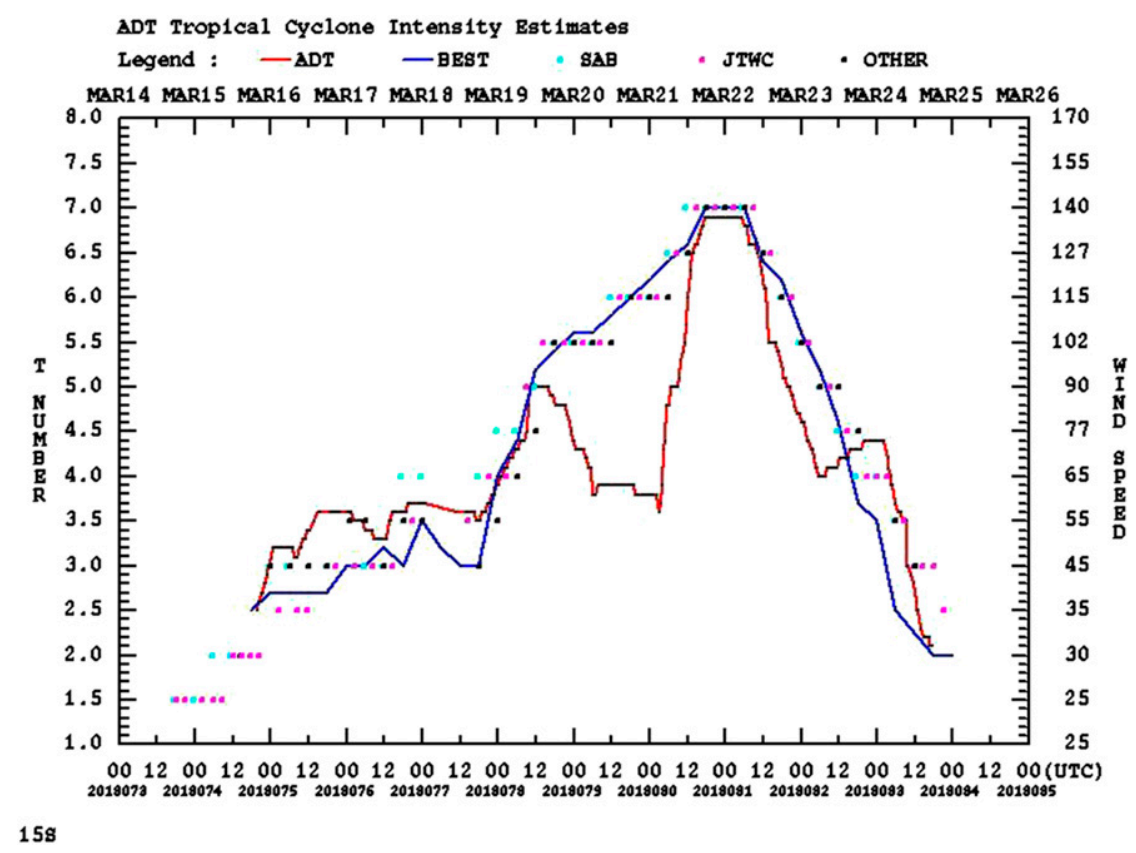

FIG. 16. ADT Vmax (kt) estimates (red) compared with JTWC best track (blue) and operational Dvorak estimates from SAB, JTWC, and Australian Bureau of Meteorology for Tropical Cyclone Marcus (15S) in 2018.

early on 21 September when the eye scene reappears. Since PMW data were not available to the ADT during this noneye period, the PMW adjustment could not be reinitialized, resulting in a drastically low intensity estimate. If the PMW would have been available, the ADT would have still been estimating too low, but not nearly as much as indicated. Again this case illustrates a current weakness in the ADT's ability to discern small or indistinct eyes (still resolvable by trained satellite analysts as indicated by the OpCen intensity estimates during this period).

In summary, while the newer ADT still has some unresolved issues with objectively estimating TC intensity, these are becoming less frequent and are usually identifiable with certain situations. User familiarity with inherent algorithm behaviors can help mitigate some of the known biases. The ADT developers will continue to explore ways to improve upon current versions and address the remaining limitations. But for the most part, the overall version 9 performance is showing skill at least on par with operational Dvorak TC intensity estimates, and in some cases improving upon them.

\section{Other applications}

While the ADT's original purpose was to provide an objective TC intensity estimation tool for operational purposes, it has also been utilized in studies focused on historical TC cases and climatological trends. Unlike the
Dvorak technique, which can inherit regional and subjective practices (Velden et al. 2006), the ADT can provide consistent and objective TC intensity analyses over time, which is essential for assessing climatological trends. For example, Kossin et al. (2013) utilized the ADT on homogenized HURSAT data to study global TC intensity trends. This study was recently extended and updated using ADT version 9. In another study, Velden et al. (2017) employed the ADT to reexamine and rank the historically strongest TCs from around the globe in the satellite era. Other climatological studies have been performed to help examine and improve historical Australian Bureau of Meteorology (ABoM) best track intensity records that did not have ADT estimates initially (Courtney and Burton 2018).

The ADT has also been used to examine the quality of simulated satellite imagery (Manion et al. 2015; Otkin et al. 2017). In one study, the ADT was applied to simulated IR imagery of TCs derived using the ECMWF global forecast system and a radiative transfer model (Magnusson et al. 2017) to evaluate the consistency with model-derived intensities. Finding good consistency between the ADT results from simulated images and the model intensities provide confidence in the behavior of the ADT algorithm as well as in the model processes creating the simulated satellite images.

The ADT is currently an ensemble member within the Satellite Consensus (SATCON) intensity estimation 
algorithm (Herndon and Velden 2018; C. S. Velden and D. Herndon 2019, unpublished manuscript). This routine derives a situationally dependent weighted consensus TC intensity estimate from several independent satellite-based sources. The weights for the ADT information are primarily dependent upon the current IR scene type.

\section{Algorithm status and availability}

The ADT version 9 was released to the real-time UW-CIMSS tropical cyclone web page in 2018, which provides nonoperational intensity estimates for all global TCs. Estimates are also provided to the ATCF, and most, if not all, of the major TC OpCens utilize the ADT estimates produced either on the CIMSS TC website, at SAB, or at their local OpCens. The ADT version 9 is being implemented into $\mathrm{SAB}$ operations and is expected to be activated in time for the 2019 Northern Hemisphere TC season.

For research purposes, historical ADT analyses are archived on the UW-CIMSS ADT website and can be accessed (http://tropic.ssec.wisc.edu/real-time/adt/adt.html). The ADT version 9 software package can also be applied for from the UW-CIMSS ADT website; however, it is recommended that sites without access to the multitude of necessary ADT data inputs should cautiously pursue this option due to the complexity of the integration and execution processes.

\section{Summary and future directions}

The advanced Dvorak technique has matured into an operationally reliable algorithm to derive tropical cyclone intensity estimates using geostationary IR satellite imagery. The ADT has been continually improved though the implantation of new techniques, statistical analysis of the algorithm performance, and suggestions from users. The completely automated intensity estimates provide an objective complement to those achieved manually by various operational TC forecast centers using the subjective Dvorak technique. Using new techniques outlined above, the latest version of the ADT can now provide intensity estimates in situations where the Dvorak technique cannot be applied, such as for ET and ST storms. The ADT can now also provide continuous estimates of outer vortex surface wind radii, and operate with the new generation of higher spatiotemporal geostationary satellite sensors.

Many of the new techniques implemented in the latest version of the ADT have been the result of collaborative research efforts to provide new functionalities significantly beyond those in the original Dvorak technique derived by Vern Dvorak in the 1970s and 1980s. Continued development of the ADT is planned. Improvements to various aspects of the ADT behavior as documented in the previous section will strengthen the performance. Expanding the ADT operability to include predepression systems is another goal. Developing ADT intensity estimate confidence indicators will help influence forecaster use of the information, and better characterize the quality of the estimates imported into the SATCONweighted consensus method.

Acknowledgments. Development of the ADT would not have been possible without the support from Jeff Hawkins and NRL/MRY, and the NOAA/NESDIS GOES programs. The authors wish to acknowledge the following individuals for their contributions or insights into making this a better product: Anthony Wimmers, Clark Evans, John Knaff, Derrick Herndon, Jim Kossin, Josh Cossuth, Robert Hart, Joe Courtney, Andrew Burton, Jack Beven, Mike Turk, Liqun Ma, John Sears, and Tim Marchok. We would also like to thank the NHC, JTWC, SAB, and CPHC for their general forecaster feedback on the real-time performance of the ADT in their operations. We applaud the suggestions from the many ADT users who motivated operability and performance improvements. Finally, we wish to acknowledge and thank the TC recon air crews (USAF and NOAA/NESDIS) for providing critical in situ intensity measurements for ADT cal/val.

\section{REFERENCES}

Berg, R., 2018: National Hurricane Center Tropical Cyclone Report: Hurricane Jose (5-22 September 2017). Tech. Rep. AL122017, National Hurricane Center, 36 pp., https:// www.nhc.noaa.gov/data/tcr/AL122017_Jose.pdf.

Cangialosi, J. P., A. S. Latto, and R. Berg, 2018: National Hurricane Center Tropical Cyclone Report: Hurricane Irma (30 August12 September 2017). Tech. Rep. AL112017, National Hurricane Center, 111 pp., https://www.nhc.noaa.gov/data/tcr/AL112017_ Irma.pdf.

Courtney, J., and J. Knaff, 2009: Adapting the Knaff and Zehr wind-pressure relationship for operational use in Tropical Cyclone Warning Centres. Aust. Meteor. Oceanogr. J., 58, 167-179, https://doi.org/10.22499/2.5803.002.

— tropical cyclone reanalysis. Final Rep., 87 pp. [Available from joe.courtney@bom.gov.au upon request.]

Dvorak, V., 1975: A technique for the analysis and forecasting of tropical cyclone intensities from satellite pictures. Mon. Wea. Rev., 103, 420-430, https://doi.org/10.1175/1520-0493(1975) $103<0420$ :TCIAAF $>2.0$. CO;2.

1984: Tropical cyclone intensity analysis using satellite data. NOAA Tech. Rep. NESDIS 11, NOAA, 47 pp., https:// satepsanone.nesdis.noaa.gov/pub/Publications/Tropical/Dvorak_ 1984.pdf. 
Hart, R. E., 2003: A cyclone phase space derived from thermal wind and thermal asymmetry. Mon. Wea. Rev., 131, 585-616, https:// doi.org/10.1175/1520-0493(2003)131<0585:ACPSDF>2.0.CO;2.

Hawkins, J. D., T. F. Lee, K. Richardson, C. Sampson, F. J. Turk, and J. E. Kent, 2001: Satellite multisensor tropical cyclone structure monitoring. Bull. Amer. Meteor. Soc., 82, 567-578, https:// doi.org/10.1175/1520-0477(2001)082<0567:RIDOSP > 2.3.CO;2.

Herndon, D., and C. Velden, 2018: An update on the CIMSS SATellite CONsensus (SATCON) Tropical Cyclone Intensity Algorithm. 33rd Conf. on Hurricanes and Tropical Meteorology, Ponta Vedra, FL, Amer. Meteor. Soc., 284, https://ams.confex.com/ams/33HURRICANE/webprogram/ Paper340235.html.

Klotz, B. W., and E. W. Uhlhorn, 2014: Improved stepped frequency microwave radiometer tropical cyclone surface winds in heavy precipitation. J. Atmos. Oceanic Technol., 31, 2392-2408, https:// doi.org/10.1175/JTECH-D-14-00028.1.

Knaff, J. A., and R. M. Zehr, 2007: Reexamination of tropical cyclone wind-pressure relationships. Wea. Forecasting, 22, 71-88, https://doi.org/10.1175/WAF965.1.

— C. C. Slocum, K. D. Musgrave, C. R. Sampson, and B. R. Strahl, 2016: Using routinely available information to estimate tropical cyclone wind structure. Mon. Wea. Rev., 144, 1233-1247, https://doi.org/10.1175/MWR-D-15-0267.1.

Koide, N., 2016: Satellite TC analysis in operations at RSMC Tokyo-Typhoon Center: Major changes since 2011. Second Int. Workshop on Satellite Analysis of Tropical Cyclones (IWSATC-II), Honolulu, HI, RSMC Tokyo-Typhoon Center, 20 pp., http://www.wmo.int/pages/prog/www/tcp/documents/ 1.5_SatTC-AnalysisInOperations-Changes_RSMCTokyo_ NaohisaKOIDE.pdf.

Kossin, J. P., T. L. Olander, and K. R. Knapp, 2013: Trend analysis with a new global record of tropical cyclone intensity. J. Climate, 26, 9960-9976, https://doi.org/10.1175/JCLI-D-13-00262.1.

Magnusson, L., M. Dahoui, C. S. Velden, and T. L. Olander, 2017: A fresh look at tropical cyclone intensity estimates. ECMWF Newsletter, No. 152, ECMWF, Reading, United Kingdom, https://www.ecmwf.int/en/newsletter/152/news/ fresh-look-tropical-cyclone-intensity-estimates.

Manion, A., C. Evans, T. L. Olander, C. S. Velden, and L. D. Grasso, 2015: An evaluation of advanced Dvorak technique-derived tropical cyclone intensity estimates during extratropical transition using synthetic satellite imagery. Wea. Forecasting, 30, 984-1009, https://doi.org/10.1175/WAF-D-15-0019.1.

Olander, T. L., and C. S. Velden, 2007: The advanced Dvorak technique: Continued development of an objective scheme to estimate tropical cyclone intensity using geostationary infrared satellite imagery. Wea. Forecasting, 22, 287-298, https://doi.org/10.1175/WAF975.1.

—_, and — 2016: The current status of the UW-CIMSS Advanced Dvorak Technique (ADT). 32nd Conf. on Hurricanes and Tropical Meteorology, San Juan, Puerto Rico, Amer. Meteor. Soc., P75, https://ams.confex.com/ams/32Hurr/ webprogram/Paper292775.html.

- _ — , and M. A. Turk, 2002: Development of the advanced objective Dvorak technique (AODT) - Current progress and future directions. Preprints, 25th Conf. on Hurricanes and Tropical Meteorology, San Diego, CA, Amer. Meteor. Soc., 15A.4, https://ams.confex.com/ams/pdfpapers/35977.pdf.

Otkin, J. A., W. E. Lewis, A. J. Lenzen, B. D. McNoldy, and S. J. Majumdar, 2017: Assessing the accuracy of the cloud and water vapor fields in the Hurricane WRF (HWRF) Model using satellite infrared brightness temperatures. Mon. Wea. Rev., 145, 2027-2046, https://doi.org/10.1175/MWR-D-160354.1.

Sampson, C. R., and A. J. Schrader, 2000: The automated tropical cyclone forecasting system (version 3.2). Bull. Amer. Meteor. Soc., 81, 1231-1240, https://doi.org/10.1175/1520-0477(2000) $081<1231$ :TATCFS $>2.3$.CO;2.

Sears, J., T. Olander, and C. Velden, 2010: Recent statistical analyses of the Advanced Dvorak Technique (ADT). 29th Conf. on Hurricanes and Tropical Meteorology, Tuscon, AZ, Amer. Meteor. Soc., 3D.5a, https://ams.confex.com/ ams/29Hurricanes/techprogram/paper_167744.htm.

Velden, C. S., T. L. Olander, and R. M. Zehr, 1998: Development of an objective scheme to estimate tropical cyclone intensity from digital geostationary satellite infrared imagery. Wea. Forecasting, 13, 172-186, https://doi.org/10.1175/ 1520-0434(1998)013<0172:DOAOST >2.0.CO;2.

— , and Coauthors, 2006: The Dvorak tropical cyclone intensity estimation technique: A satellite-based method that has endured for over 30 years. Bull. Amer. Meteor. Soc., 87, 1195-1210, https://doi.org/10.1175/BAMS-87-9-1195.

_ , T. L. Olander, D. Herndon, and J. P. Kossin, 2017: Reprocessing the most intense historical tropical cyclones in the satellite era using the advanced Dvorak technique. Mon. Wea. Rev., 145, 971-983, https://doi.org/10.1175/MWR-D-16-0312.1.

Wimmers, A. J., and C. S. Velden, 2010: Objectively determining the rotational center of tropical cyclones in passive microwave satellite imagery. J. Appl. Meteor. Climatol., 49, 2013-2034, https://doi.org/10.1175/2010JAMC2490.1.

$\longrightarrow$, and - 2016: Advancements in objective multisatellite tropical cyclone center fixing. J. Appl. Meteor. Climatol., 55, 197-212, https://doi.org/10.1175/JAMC-D-15-0098.1. 